\title{
EFECTIVITY OF COST CONTROLLING AND WORKING CAPITAL TURN- OVER OF ECONOMICAL RENTABILITY
}

Case study behalf PT. Astra Argo Lestari, Tbk. and PT. Perusahaan Perkebunan London Sumatra Indonesia, Tbk.

\author{
AMATUS SYAKUR SADIQAH AND YOYON SUPRIADI. \\ STIE KESATUAN
}

\begin{abstract}
Capital adequacy can be done in many ways, such as by owned-self company capital contaied of fee balanced, stock holder's capital, and both of them. Beside supported by right fullfillment of network capital, in order to develop the company in better ways , the efectivity, efeciency and productiveness will be very influencing the company.

The purpose of this research it to knowing the efectivity of capital maintenance, turnover rate of capital networking and economical rentability of PT. Astra Agro Lestari, Tbk. and PT. Perusahaan Perkebunan London Sumatra Indonesia, Tbk. to determine the effect of cost control and turnover rate capital networking to economical rentability of PT PT. Astra Agro Lestari, Tbk. and PT. Perusahaan Perkebunan London Sumatra Indonesia, Tbk.

From the result of 12 years analysis, the effectivity of cost control of PT. Astra Agro Lestari, Tbk. produce an average of $33,8 \%$ bigger than PT. Perusahaan Perkebunan London Sumatra Indonesia, Tbk. which produce only $30.5 \%$. the working capital turnover of PT. Astra Agro Lestari, Tbk. produce an average of 4.99 times much bigger than PT. Perusahaan Perkebunan London Sumatra Indonesia, Tbk. which only produce an average of 2.87 times. And for the rentability, PT. Astra Agro Lestari, Tbk. produce 23.07\% bigger than PT. Perusahaan Perkebunan London Sumatra Indonesia, Tbk. which produce an average of $14.5 \%$. the statistic result by using SPSS Ver.20.0 application, explained that the effectiveness effect of OPM's cost control and working capital tunover to economical rentability of PT. Astra Agro Lestari, Tbk. and PT. Perusahaan Perkebunan London Sumatra Indonesia, Tbk.

For PT. Astra Agro Lestari, Tbk. and PT. Perusahaan Perkebunan London Sumatra Indonesia, Tbk, are advices in order to press the cost of its operatios and selling cost to gain more profits. Beside that, the companies are advices in order to accelerate their networking capital, so that the companies activities can work properly by increasing its selling chart and press selling cost will gain the profits to maximum.
\end{abstract}

Keywords: cost control effectivity, working capital turnover, economical rentability.

\section{PENDAHULUAN}

\subsection{Latar Belakang}

Perekonomian Indonesia saat ini sedang menuju pada era globalisasi yang memberikan peluang bagi perusahaan-perusahaan untuk mengembangkan usahanya. Dilain pihak dengan adanya perdagangan bebas pada era globalisasi ini menimbulkan persaingan yang ketat, dan perusahaan harus mampu mengantisipasi dan menghadapi segala situasi dan kondisi agar mampu bertahan dan dapat terus maju dalam rangka memenangkan persaingan usaha.

Guna menghadapi persaingan yang semakin ketat tersebut maka perusahaan harus mampu mengelola masalah-masalah vitalnya. Masalah keuangan merupakan salah satu masalah yang sangat vital bagi perusahaan 
dalam perkembangan bisnisnya dan pencapaian tujuannya. Salah satu tujuan utama didirikannya perusahaan adalah untuk memperoleh keuntungan yang maksimal. Namun berhasil tidaknya perusahaan dalam mencari keuntungan dan mempertahankan perusahaannya tergantung pada manajemen keuangan. Perusahaan harus memiliki kinerja keuangan yang sehat dan efisien untuk mendapatkan keuntungan atau laba. Kinerja keuangan merupakan hal yang penting bagi setiap perusahaan didalam persaingan bisnis untuk mempertahankan perusahaannya.

Kemampuan perusahaan dalam menghasilkan keuntungan adalah kunci keberhasilan perusahaan untuk dapat dikatakan mempunyai kinerja perusahaan yang baik, karena keuntungan merupakan komponen laporan keuangan yang digunakan sebagai alat untuk menilai baik tidaknya kinerja perusahaan. Hal ini akan mempengaruhi keberlangsungan perusahaan untuk maju dan berkerjasama antara perusahaan yang satu dengan perusahaan yang lain.

Agar laba tetap terpelihara, manajemen perlu mengefektivitaskan pengendalian biaya tanpa harus mengurangi kualitas dan kuantitas produk yang ditetapkan, sehingga perusahaan dapat hidup dan beroperasi. Biaya perlu dikendalikan karena biaya sangat mempengaruhi rentabilitas suatu usaha.

Salah satu tugas manajer keuangan adalah mengambil keputusan pembelanjaan. Dalam kondisi baik, perusahaan yang porsi penggunaan utangnya lebih besar dari pada modal sendiri mampu menghasilkan laba besar bagi pemegang saham dibandingkan dengan perusahaan yang porsi penggunaan utangnya lebih kecil dari modal sendiri. Sebaliknya dalam kondisi ekonomi yang buruk, perusahaan yang porsi penggunaan utangnya lebih besar dari pada modal sendiri akan menghasilkan laba yang lebih kecil bagi pemegang saham dibandingkan dengan perusahaan yang porsi pengunaan utangnya lebih kecil dari pada modal sendiri.

Dalam menjalankan usahanya, manajer perusahaan tidak akan terlepas dari masalah permodalan perusahaan yaitu pemenuhan modal kerja maupun investasi. Bahkan apabila perusahaan telah mencapai posisi tertentu yang cukup sesuai dengan tujuan, maka perusahaan tersebut dapat melakukan ekspansi atau perluasan usaha. Dalam melakukan ekspansi, suatu perusahaan tidak akan terlepas dari kebutuhan akan modal. Pemenuhan kebutuhan modal tersebut dapat dilakukan dengan berbagai cara, anatara lain dengan modal sendiri yang terdiri dari saldo laba, modal dari pemegang saham dan dari sumber lainnya yaitu modal pinjaman atau dapat pula diperoleh dengan mengkombinasikan keduanya

Yang tidak kalah penting adalah biaya modal perusahaan. Biaya modal (cost of capital) perusahaan merupakan salah satu tolak ukur untuk menilai apakah keputusan pembelanjaan yang diambil pihak perusahaan sudah merupakan keputusan yang optimal, disamping nilai perusahaan atau harga pasar saham. Biaya modal juga penting untuk menilai kelayakan dari suatu usulan proyek investasi. Peranan biaya modal dalam penilaian kelayakan suatu usulan investasi tergantung metode yang digunakan. Pada metode NPV, biaya modal berfungsi sebagai tingkat diskonto (discount rate), sedangkan pada metode IRR biaya modal berfungsi sebagai cut-off rate. 
Berdasarkan masalah di atas dan persoalan yang dihadapi oleh perusahaan maka dalam menyusun skripsi ini penulis mengambil judul "Pengaruh Efektivitas Pengendalian Biaya dan Tingkat Perputaran Modal Kerja Terhadap Rentabilitas Perusahaan"

\subsection{Identifikasi Masalah}

Atas dasar tersebut maka penulis akan mengidentifikasi maslaah sebagai berikut:

1. Bagaimana pengaruh efektifitas pengendalian biaya terhadap rentabilitas ekonomi perusahaan?

2. Bagaiamana pengaruh perputaran modal kerja terhadap rentabilitas ekonomi perusahaan?

3. Bagaimana pengaruh efektivitas pengendalian biaya dan perputaran modal kerja terhadap rentabilitas ekonomi perusahaan?

\subsection{Maksud dan Tujuan Penelitian}

Tujuan yang diharapkan dari penelitian ini adalah:

1. Untuk mengetahui efektivitas pengendalian biaya di dalam perusahaan.

2. Untuk mengetahui perputaran modal kerja di dalam perusahaan.

3. Untuk mengetahui rentabilitas ekonomi perusahaan.

4. Untuk mengetahui pengaruh efektivitas pengendalian biaya terhadap rentabilitas ekonomi perusahaan.

5. Untuk mengetahui pengaruh perputaran modal kerja terhadap rentabilitas ekonomi perusahaan.

6. Untuk mengetahui pengaruh efektivitas pengendalian biaya dan modal kerja terhadap rentabilitas ekonomi perusahaan.

\section{TINJAUAN PUSTAKA}

Pengendalian pada prinsipnya dapat memperhatikan suatu kegiatan dan selalu mengawasi aktivitas sehari-hari, maka pengendalian biaya adalah proses atau usaha yang sistimatis dalam penetapan standar pelaksanaan dengan tujuan perencanaan, sistem informasi umpan balik, membandingkan pelaksanaan nyata dengan perencanaan menentukan dan mengatur penyimpangan-penyimpangan serta melakukan koreksi perbaikan sesuai dengan rencana yang telah ditetapkan, sehingga tujuan tercapai secara efektif dan efisien dalam penggunaan biaya.

Menurut Lawrence J Gitman (2006:628) modal kerja adalah "current assets,commonly called working capital, represent the portion of investment that circulates from one form to another in the ordinary conduct of business".

Definisi lain dikemukakan Lukman Syamsuddin (2007:200) yakni "modal kerja berhubungan dengan current account (perkiraan aktiva lancar dan utang lancar) perusahaan". 
Rentabilitas ekonomi adalah perbandingan antara laba usaha dengan modal sendiri dan modal asing yang dipergunakan untuk menghasilkan laba tersebut dan dinyatakan dalam presentase. Rentabilitas merupakan suatu alat untuk menilai keberhasilan suatu (perusahaan) koperasi dalam memperoleh laba/SHU. Pada dasarnya peningkatan rentabilitas dari periode ke periode menunjukkan adanya kemajuan yang dicapai Koperasi, akan tetapi jika kenaikan rentabilitas itu juga diikuti dengan kenaikan biaya yang relatif besar dan perputaran modal kerja yang relatif lambat maka hal ini menunjukkan belum efektifnya Koperasi dalam mengelola usaha.

\section{Hipotesis Penelitian}

Analisis Kuantitatif sebagai berikut:

a. Diduga ada pengaruh antara modal sendiri dan modal pinjaman terhadap tingkat rentabilitas.

b. Diduga pengendalian biaya dan modal kerja sangat berpengaruh terhadap rentabilitas.

c. Diduga efesiensi modal kerja dan likuiditas berpengaruh terhadap rentabilitas ekonomi. 


\section{Kerangka Pemikiran Konseptual}

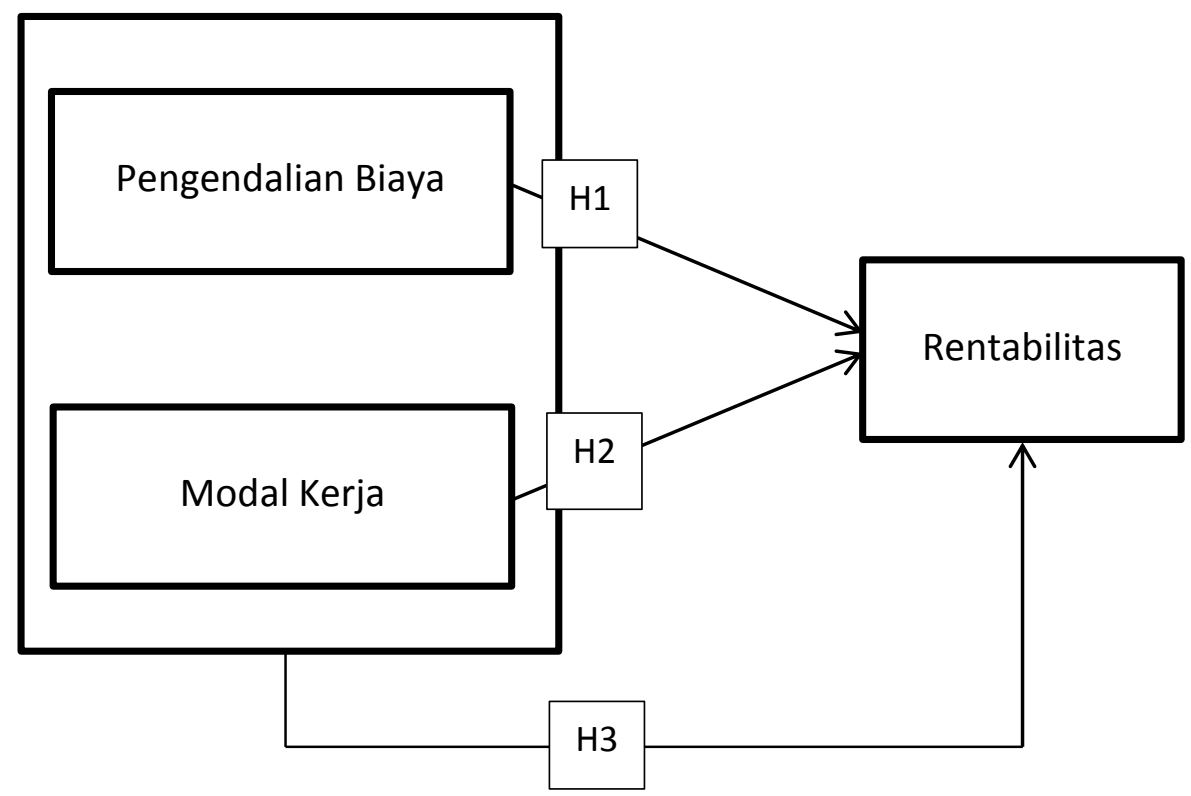

\section{METODELOGI PENELITIAN}

\section{Lokasi Dan Waktu Penelitian}

Lokasi untuk mencari data yang digunakan berada dilaboratorium Bursa Efek Indonesia STIE Kesatuan dan www.idx.co.id. Sampel penelitian ini diambil selama 12 tahun yaitu dari 2002 sampai dengan tahun 2013.

\section{Metode Penelitian}

Dalam penelitian ini metode yang digunakan oleh penulis adalah metode penelitian deskriptif komparatif, rasio dan statistik. Metode penelitian ini adalah suatu metode yang dilakukan dengan mencari data yang dapat memberikan gambaran yang jelas, sistematik, faktual dan akurat yang berkaitan dengan variabel-variabel yang dibahas, yakni financial leverage dan operating leverage terhadap profitabilitas.

\section{Operasionalisasi Variabel}

Operasional variabel diperlukan untuk menentukan jenis, indikator, serta skala dari variabel-variabel yang terkait pada penelitian, sehingga pengujian hipotesis denngan alat bantu statistik dapat dilakukan secara benar, maka dalam penelitian ini terdapat dua variabel yang digunakan yaitu:

\begin{tabular}{|c|c|c|}
\hline Variabel/ Sub Variabel & Indikator & Skala/ Ukuran \\
\hline Efektivitas Pengendalian Biaya & Operating Profit Margin & Rasio \\
\hline Perputaran Modal Kerja & Working Capital Turn Over & Rasio \\
\hline Rentabilitas & Return On Asset & Rasio \\
\hline
\end{tabular}

Jenis dan Sumber Data 
Jenis data yang digunakan peneliti dalam penelitian mengenai "Pengaruh Efektivitas Pengendalian Biaya dan Perputaran Modal Kerja Terhadap Rentabilitas Ekonomi" adalah dengan menggunakan data sekunder.

\section{Prosedur Pengumpulan Data}

Untuk memperoleh data dan keterangan serta informasi yang diperlukan untuk mendukung penelitian ini, maka penulis mengumpulkan data melalui:

1. Studi Kepustakaan

Studi kepustakaan adalah salah satu bentuk penelitian yang dilakukan guna memperoleh informasi dan data yang dibutuhkan dalam penelitian berdasarkan buku-buku dan literatur yang diperlukan sehingga diperoleh pengertian teoritis yang diperlukan untuk menganalisis data yang diperoleh.

2. Studi Lapangan

Merupakan metode penulisan dengan cara memperoleh data dan informasi langsung dari perusahaan yaitu dengan cara observasi, tetapi pengambilan data tidak terjun langsung keperusahaan tetapi berupa data sekunder. Dalam hal ini pengumpulan data dari situs perusahaan yang diteliti.

3. Internet

Selain diri studi keperpustakaan, penulis juga mengumpulkan informasi yang diperoleh dari internet. Penulis melakukan browsing mengenai hal-hal berkaitan dengan data yang dibutuhkan untuk mempermudah penelitian.

\section{Metode Analisis}

Untuk menganalisis identifikasi masalah, penulis menggunakan metode analisis sebagai berikut:

1. Operating Profit Margin

Operating Profit Margin adalah rasio yang digunakan untuk mengukur kemampuan perusahaan dalam menghasilkan keuntungan. Operating profit margin mengukur persentase dari profit yang diperoleh perusahaan dari tiap penjualan sebelum dikurangi dengan biaya bunga dan pajak. Pada umumnya semakin tinggi rasio ini maka semakin baik. Formula: Operating Profit Margin = EBIT / Sales Revenue

\section{Working Capital Turn Over}

Perputaran modal kerja merupakan rasio mengukur aktivitas bisnis terhadap kelebihan aktiva lancar atas kewajiban lancar serta menunjukkan banyaknya penjualan (dalam rupiah) yang dapat diperoleh perusahaan untuk tiap rupiah modal kerja, perputaran modal kerja dimulai saat dimana kas diinvestasikan dalam komponen-komponen modal kerja sampai dimana saat kembali menjadi kas. Makin pendek periode tersebut berarti makin cepat perputaran atau makin tinggi perputarannya. Berapa lama periode perputaran modal kerja adalah tergantung berapa lama periode perputaran dari masingmasing komponen dari modal kerja tersebut. 


\section{Return On Asset}

Bentuk dari rasio profitabilitas untuk mengukur kemampuan perusahaan dalam menghasilkan laba dengan menggunakan total aktiva yang ada dan setelah biaya-biaya modal (biaya yang digunakan mendanai aktiva) dikeluarkan dari analisis. Return On Asset adalah rasio keuntungan bersih pajak yang juga berarti suatu ukuran untuk menilai seberapa besar tingkat pengembalian dari asset yang dimiliki perusahaan. Return On Asset yang positif menunjukan bahwa total aktiva yang dipergunakan untuk operasi perusahaan memberikan laba bagi perusahaan. Sebaliknya jika hasi dari Return On Asset negatif menunjukan total aktiva yang digunakan tidak memberikan keuntungan.

\section{Formula: Return On Asset $=$ Net Income $/$ Total Asset}

\section{Hasil dan Pembahasan}

\section{OPM PT. Astra Agro Lestari}

\begin{tabular}{|c|c|c|c|c|c|}
\hline Tahun & EBIT & $\Delta$ EBIT & Sales Revenue & $\Delta$ SR & OPM \\
\hline 2002 & 587.806 & & 2.031 .478 & & $28,9 \%$ \\
2003 & 753.640 & $28,21 \%$ & 2.543 .157 & $25,19 \%$ & $29,6 \%$ \\
2004 & 1.284 .812 & $70,48 \%$ & 3.472 .524 & $36,54 \%$ & $37,0 \%$ \\
2005 & 1.198 .615 & $-6,71 \%$ & 3.370 .936 & $-2,93 \%$ & $35,6 \%$ \\
2006 & 1.198 .597 & $0,00 \%$ & 3.757 .987 & $11,48 \%$ & $31,9 \%$ \\
2007 & 2.906 .045 & $142,45 \%$ & 5.960 .954 & $58,62 \%$ & $48,8 \%$ \\
2008 & 3.377 .344 & $16,22 \%$ & 8.161 .217 & $36,91 \%$ & $41,4 \%$ \\
2009 & 2.610 .218 & $-22,71 \%$ & 7.424 .283 & $-9,03 \%$ & $35,2 \%$ \\
2010 & 2.998 .711 & $14,88 \%$ & 8.843 .721 & $19,12 \%$ & $33,9 \%$ \\
2011 & 3.195 .661 & $6,57 \%$ & 10.772 .582 & $21,81 \%$ & $29,7 \%$ \\
2012 & 3.453 .729 & $8,08 \%$ & 11.564 .319 & $7,35 \%$ & $29,9 \%$ \\
2013 & 3.004 .546 & $-13,01 \%$ & 12.674 .999 & $9,60 \%$ & $23,7 \%$ \\
\hline Min & 587.806 & $-22,71 \%$ & 2.031 .478 & $-9,03 \%$ & $23,7 \%$ \\
Max & 3.453 .729 & $142,45 \%$ & 12.674 .999 & $58,62 \%$ & $48,8 \%$ \\
Rata-rata & 2.214 .144 & $22,22 \%$ & 6.714 .846 & $19,52 \%$ & $33,8 \%$ \\
\hline
\end{tabular}

PT. Astra Agro Lestari, Tbk selama periode tahun 2002 sampai dengan tahun 2013 memiliki nilai rata-rata 33,8\%, nilai maksimal 48,8\% dan nilai minimal $23,7 \%$ selama 12 tahun terakhir. 
OPM PT. Perusahaan Perkebunan London Sumatra Indonesia, Tbk

\begin{tabular}{|c|c|c|c|c|c|}
\hline Tahun & EBIT & $\Delta$ EBIT & Sales Revenue & $\Delta$ SR & OPM \\
\hline 2002 & 326.367 & & 1.098 .056 & & $29,7 \%$ \\
2003 & 313.103 & $-4,06 \%$ & 1.256 .785 & $14,46 \%$ & $24,9 \%$ \\
2004 & 459.216 & $46,67 \%$ & 1.654 .294 & $31,63 \%$ & $27,8 \%$ \\
2005 & 443.848 & $-3,35 \%$ & 1.832 .860 & $10,79 \%$ & $24,2 \%$ \\
2006 & 454.648 & $2,43 \%$ & 2.148 .413 & $17,22 \%$ & $21,2 \%$ \\
2007 & 990.900 & $117,95 \%$ & 2.900 .835 & $35,02 \%$ & $34,2 \%$ \\
2008 & 1.314 .416 & $32,65 \%$ & 3.846 .154 & $32,59 \%$ & $34,2 \%$ \\
2009 & 1.018 .651 & $-22,50 \%$ & 3.199 .687 & $-16,81 \%$ & $31,8 \%$ \\
2010 & 1.399 .520 & $37,39 \%$ & 3.592 .658 & $12,28 \%$ & $39,0 \%$ \\
2011 & 2.005 .524 & $43,30 \%$ & 4.686 .457 & $30,45 \%$ & $42,8 \%$ \\
2012 & 1.323 .973 & $-33,98 \%$ & 4.211 .578 & $-10,13 \%$ & $31,4 \%$ \\
2013 & 1.025 .649 & $-22,53 \%$ & 4.133 .679 & $-1,85 \%$ & $24,8 \%$ \\
\hline Min & 313.103 & $-33,93 \%$ & 1.098 .056 & $-16,81 \%$ & $21,2 \%$ \\
Max & 2.003 .976 & $117,95 \%$ & 4.686 .467 & $35,02 \%$ & $42,8 \%$ \\
Rata-rata & 922.856 & $17,63 \%$ & 2.880 .121 & $14,15 \%$ & $30,5 \%$ \\
\hline
\end{tabular}

PT. Perusahaan Perkebunan London Sumatra Indonesia, Tbk selama periode tahun 2002 sampai dengan tahun 2013 memiliki nilai rata-rata 30,5\%, nilai maksimal $42,8 \%$ dan nilai minimal $21,2 \%$ selama 12 tahun terakhir. 
WCTO PT. Astra Agro Lestari, Tbk

\begin{tabular}{|c|c|c|c|c|c|}
\hline Tahun & Penjualan & $\Delta$ Penjualan & Aktiva Lancar & $\Delta$ AL & WCTO \\
\hline 2002 & 2.031 .478 & & 442.678 & & 4,59 \\
2003 & 2.543 .157 & $25,19 \%$ & 664.208 & 0,50 & 3,83 \\
2004 & 3.472 .524 & $36,54 \%$ & 1.243 .319 & 0,87 & 2,79 \\
2005 & 3.370 .936 & $-2,93 \%$ & 691.345 & $-0,44$ & 4,88 \\
2006 & 3.757 .987 & $11,48 \%$ & 492.195 & $-0,29$ & 7,64 \\
2007 & 5.960 .954 & $58,62 \%$ & 1.647 .854 & 2,35 & 3,62 \\
2008 & 8.161 .217 & $36,91 \%$ & 1.975 .656 & 0,20 & 4,13 \\
2009 & 7.424 .283 & $-9,03 \%$ & 1.714 .426 & $-0,13$ & 4,33 \\
2010 & 8.843 .721 & $19,12 \%$ & 2.051 .177 & 0,20 & 4,31 \\
2011 & 10.772 .582 & $21,81 \%$ & 1.887 .387 & $-0,08$ & 5,71 \\
2012 & 11.564 .319 & $7,35 \%$ & 1.780 .395 & $-0,06$ & 6,50 \\
2013 & 12.674 .999 & $9,60 \%$ & 1.691 .694 & $-0,05$ & 7,49 \\
\hline Min & 2.031 .478 & $19,52 \%$ & 442.678 & $-0,44$ & 2,79 \\
Max & 112.674 .999 & $58,62 \%$ & 2.051 .177 & 2,35 & 7,64 \\
Rata- & 6.714 .846 & $19,52 \%$ & 1.356 .861 & 0,27 & 4,98 \\
rata & & & & & \\
\hline
\end{tabular}

PT. Astra Agro Lestari, Tbk selama periode tahun 2002 sampai dengan tahun 2013 memiliki nilai perputaran rata-rata 4,98 kali, nilai maksimal 7,64 kali dan nilai minimal 2,79 kali selama 12 tahun terakhir.

WCTO PT. Perusahaan Perkebuanan London Sumatra Indonesia, Tbk

\begin{tabular}{|c|c|c|c|c|c|}
\hline Tahun & Penjualan & $\Delta$ Penjualan & Aktiva Lancar & $\Delta \mathrm{AL}$ & WCTO \\
\hline 2002 & 1.098 .056 & & 357.636 & & 3,07 \\
2003 & 1.256 .785 & $14,46 \%$ & 633.341 & $77,09 \%$ & 1,98 \\
2004 & 1.654 .294 & $31,63 \%$ & 415.065 & $-34,46 \%$ & 3,99 \\
2005 & 1.832 .860 & $10,79 \%$ & 397.512 & $-4,23 \%$ & 4,61 \\
2006 & 2.148 .413 & $17,22 \%$ & 539.735 & $35,78 \%$ & 3,98 \\
2007 & 2.900 .835 & $35,02 \%$ & 1.005 .778 & $86,35 \%$ & 2,88 \\
2008 & 3.846 .154 & $32,59 \%$ & 1.445 .800 & $43,75 \%$ & 2,66 \\
2009 & 3.199 .687 & $-16,81 \%$ & 964.362 & $-33,30 \%$ & 3,32 \\
2010 & 3.592 .658 & $12,28 \%$ & 1.487 .257 & $54,22 \%$ & 2,42 \\
2011 & 4.686 .457 & $30,45 \%$ & 2.567 .657 & $72,64 \%$ & 1,83 \\
2012 & 4.211 .578 & $-10,13 \%$ & 2.593 .816 & $1,02 \%$ & 1,62 \\
2013 & 4.133 .679 & $-1,85 \%$ & 1.999 .126 & $-22,93 \%$ & 2,07 \\
\hline Min & 1.098 .056 & $-16,81 \%$ & 357.636 & $-34,46 \%$ & 1,62 \\
Max & 4.686 .457 & $35,02 \%$ & 2.593 .186 & $86,35 \%$ & 4,61 \\
Rata-rata & 2.880 .121 & $14,15 \%$ & 1.200 .590 & $25,08 \%$ & 2,87 \\
\hline
\end{tabular}

PT. Perusahaan Perkebunan London Sumatra Indonesia, Tbk selama periode tahun 2002 sampai dengan tahun 2013 memiliki nilai perputaran ratarata 2,87 kali, nilai maksimal 4,61 kali dan nilai minimal 1,62 kali selama 12 tahun terakhir. 
Return On Asset PT. Astra Agro Lestari, Tbk

\begin{tabular}{|c|c|c|c|c|c|}
\hline Tahun & Net Income & $\Delta$ Net Income & Total Asset & $\Delta$ TA & ROA \\
\hline 2002 & 237.797 & & 2.611 .601 & & $9,1 \%$ \\
2003 & 291.386 & $22,54 \%$ & 2.843 .823 & $8,89 \%$ & $10,2 \%$ \\
2004 & 830.867 & $185,14 \%$ & 3.382 .821 & $18,95 \%$ & $24,6 \%$ \\
2005 & 816.549 & $-1,72 \%$ & 3.191 .715 & $-5,65 \%$ & $25,6 \%$ \\
2006 & 814.031 & $-0,31 \%$ & 3.496 .955 & $9,56 \%$ & $23,3 \%$ \\
2007 & 2.039 .907 & $150,59 \%$ & 5.352 .986 & $53,08 \%$ & $38,1 \%$ \\
2008 & 2.715 .518 & $33,12 \%$ & 6.519 .791 & $21,80 \%$ & $41,7 \%$ \\
2009 & 1.729 .648 & $-36,31 \%$ & 7.571 .399 & $16,13 \%$ & $22,8 \%$ \\
2010 & 2.103 .652 & $21,62 \%$ & 8.791 .799 & $16,12 \%$ & $23,9 \%$ \\
2011 & 2.498 .565 & $18,77 \%$ & 10.204 .495 & $16,07 \%$ & $24,5 \%$ \\
2012 & 2.520 .266 & $0,87 \%$ & 12.419 .820 & $21,71 \%$ & $20,3 \%$ \\
2013 & 1.903 .088 & $-24,49 \%$ & 14.963 .190 & $20,48 \%$ & $12,7 \%$ \\
\hline Min & 237.797 & $-36,31 \%$ & 2.611 .601 & $-5,65 \%$ & $9,1 \%$ \\
Mata-rata & 2.715 .518 & $185,14 \%$ & 14.963 .190 & $53,08 \%$ & $41,7 \%$ \\
\hline
\end{tabular}

PT. Astra Agro Lestari, Tbk selama periode tahun 2002 sampai dengan tahun 2013 memiliki nilai rata-rata 23,1\%, nilai maksimal 41,7\% dan nilai minimal $9,1 \%$ selama 12 tahun terakhir. 
Return On Asset PT. Perusahaan Perkebunan London Sumatra Indonesia, Tbk

\begin{tabular}{|c|c|c|c|c|c|}
\hline Tahun & Net Income & $\Delta$ Net Income & Total Asset & $\Delta$ TA & ROA \\
\hline 2002 & 500.909 & & 1.686 .081 & & $29,7 \%$ \\
2003 & 310.909 & $-37,93 \%$ & 2.019 .458 & $19,77 \%$ & $15,4 \%$ \\
2004 & $(247.198)$ & $-179,51 \%$ & 2.362 .930 & $17,01 \%$ & $-10,5 \%$ \\
2005 & 355.724 & $-243,90 \%$ & 2.602 .173 & $10,12 \%$ & $13,7 \%$ \\
2006 & 303.105 & $-14,79 \%$ & 2.985 .212 & $14,72 \%$ & $10,2 \%$ \\
2007 & 564.034 & $86,09 \%$ & 3.938 .140 & $31,92 \%$ & $14,3 \%$ \\
2008 & 927.555 & $64,45 \%$ & 4.931 .528 & $25,22 \%$ & $18,8 \%$ \\
2009 & 707.487 & $-23,73 \%$ & 4.852 .277 & $-1,61 \%$ & $14,6 \%$ \\
2010 & 1.033 .329 & $46,06 \%$ & 5.561 .433 & $14,61 \%$ & $18,6 \%$ \\
2011 & 1.701 .513 & $64,66 \%$ & 6.791 .859 & $22,12 \%$ & $25,1 \%$ \\
2012 & 1.115 .539 & $-34,44 \%$ & 7.551 .796 & $11,19 \%$ & $14,8 \%$ \\
2013 & 768.625 & $-31,10 \%$ & 7.974 .876 & $5,60 \%$ & $9,6 \%$ \\
\hline Min & -247.198 & $-243,90 \%$ & 1.686 .081 & $-1,40 \%$ & $-10,5 \%$ \\
Max & 1.701 .513 & $86,09 \%$ & 7.974 .876 & $31,92 \%$ & $29,7 \%$ \\
Rata-rata & 670.128 & $-27,65 \%$ & 4.437 .295 & $15,51 \%$ & $14,5 \%$ \\
\hline
\end{tabular}

PT. Perusahaan Perkebunan London Sumatra Indonesia, Tbk selama periode tahun 2002 sampai dengan tahun 2013 memiliki nilai perputaran ratarata 2,87 kali, nilai maksimal 4,61 kali dan nilai minimal 1,62 kali selama 12 tahun terakhir.

\section{Simpulan}

\section{SIMPULAN DAN SARAN}

Berdasarkan hasil dan pembahasan mengenai "Efektivitas Pengendalian Biaya dan Tingkat Perputaran Modal Kerja Terhadap Rentabilitas Ekonomi", maka dapat diambil simpulan sebagai berikut:

1. Pengaruh Efektivitas Pengendalian Biaya Terhadap Rentabilitas Ekonomi Perusahaan dengan rasio OPM (Pengaruh Efektivitas Pengendallian Biaya) dan ROA (Rentabilitas Ekonomi) pada PT. Astra Agro Lestari, Tbk adalah signifikan, dengan hasil SPSS 0,054 atau 5,4\% hasil tersebut menunjukan bahwa PT. Astra Agro Lestari, Tbk memiliki pengaruh yang cukup erat antara Efektivitas Pengendalian Biaya Terhadap Rentabilitas Ekonomi Perusahaan. Dan pada PT. Perusahaan Perkebunan London Sumatra Indonesia, Tbk tidak signifikan dengan hasil SPSS 0,295 atau 29,5\% hasil tersebut menunjukan bahwa PT. Perusahaan Perkebunan London Sumatra Indonesia, Tbk tidak memiliki pengaruh antara Efektivitas Pengendalian Biaya Terhadap Rentabilitas Ekonomi Perusahaan.

2. Pengaruh Tingkat Perputaran Modal Kerja Terhadap Rentabilitas Ekonomi Perusahaan dengan rasio WCTO ( Tingkat Perputaran Modal Kerja) dan ROA (Rentabilitas Ekonomi) pada PT. Astra Agro Lestari, Tbk 
adalah tidak signifikan, dengan hasil SPSS 0,968 atau 96,8\% hasil tersebut menunjukan bahwa PT. Astra Agro Lestari, Tbk tidak memiliki pengaruh yang antara Efektivitas Pengendalian Biaya Terhadap Rentabilitas Ekonomi Perusahaan. Dan hasil pada PT. Perusahaan Perkebunan London Sumatra Indonesia, Tbk adalah signifikan dengan hasil SPSS 0,048 atau $4,8 \%$ hasil tersebut menunjukan bahwa PT. Perusahaan Perkebunan London Sumatra Indonesia, Tbk memiliki pengaruh yang cukup erat antara Efektivitas Pengendalian Biaya Terhadap Rentabilitas Ekonomi Perusahaan.

3. Pengaruh Efektivitas Pengendalian Biaya dan Tingkat Perputaran Modal Kerja Terhadap Rentabilitas Ekonomi pada PT. Astra Agro Lestari, Tbk adalah signifikan, dengan hasil SPSS 0,039 atau 3,9\% hasil tersebut menunjukan bahwa PT. Astra Agro Lestari, Tbk memiliki pengaruh yang erat antara Efektivitas Pengendalian Biaya dan Tingkat Perputaran Modal Kerja Terhadap Rentabilitas Ekonomi. Dan pada PT. Perusahaan Perkebunan London Sumatra Indonesia, Tbk adalah signifikan, dengan hasil SPSS 0,070 atau 7\% hasil tersebut menunjukan bahwa PT. Astra Agro Lestari, Tbk memiliki pengaruh yang cukup erat antara Efektivitas Pengendalian Biaya dan Tingkat Perputaran Modal Kerja Terhadap Rentabilitas Ekonomi.

\section{Saran}

Berdasarkan hasil pembahasan dan kesimpulan diatas, maka saransaran penulis adalah sebagai berikut:

Untuk perusahaan PT. Astra Agro Lestari, Tbk. Dan PT. Perusahaan Perkebunan London Sumatra Indonesia, Tbk. Harus dapat lebih menekan biayabiaya operasional dan biaya penjualan agar keuntungan yang didapat menjadi besar dan lebih efektiv. Disamping itu harus bisa mempercepat perputaran modal kerja agar kegiatan perusahaan berjalan lancar dengan meningkatkan penjualan dan menekan biaya penjualan akan mencapai laba yang maksimal.

\section{DAFTAR PUSTAKA}

Wulandari, B. (2009). Pengaruh Efektivitas Pengendalian Biaya dan Tingkat Perputaran Modal Kerja terhadap Rentabilitas (Studi pada Koperasi Primkopti Kabupaten Blora) (Doctoral dissertation, Universitas Negeri Semarang).

Wicaksono, W. (2011). PENGARUH PENGENDALIAN BIAYA DAN TINGKAT PERPUTARAN MODAL KERJA TERHADAP RENTABILITAS EKONOMI PADA KPRI KABUPATEN BLORA TAHUN 2009-2010 (Doctoral dissertation, Universitas Negeri Semarang)

Van Horne, J. dan Jr, Wachowicz, John (2012). Prinsip-Prinsip Manajemen Keuangan. 
Van Horne, J. dan Jr, Wachowicz, John (2013). Prinsip-Prinsip Manajemen Keuangan.

Setia Atmaja, L. (2008). Teori \& Praktik Manajemen Keuangan.

Ross, Westerfiled, Jordan. (2009). Pengantar Keuangan Perusahaan. Van Horne, J. dan Jr, Wachowicz, John (2007). Fundamentals of Financial Management Prinsip-Prinsip Manajemen Keuangan.

Brigham, Huston. (2010). DASAR-DASAR MANAJEMEN KEUANGAN.

Arifin, Johar dan Sumaryono, Achmad. 2007. Buku Kerja Berbasis Komputer Untuk Manajer keuangan Dan Akuntan. Jakarta: PT Elex Media Komputindo.

Bradshaw, Mark T. 2008. Financial Reporting, Financial Statement Analysis, and Valuation. Cengage Learning: South-Western.

Brigham, Eugene F. dan Houston, Joel F. 2010. Dasar-dasar Manajemen Keuangan(Essentials Of Financial Management). Jakarta: Salemba Empat.

Fahmi, Irham. 2013. Rahasia Saham Dan Obligasi Edisi 1. Bandung: Alfabeta.

Hanafi, Mamduh M dan Halim, Abdul. 2009. Analisis Laporan Keuangan (Edisi 4). Yogyakarta: UPP STIM YKPN.

Hidayat, Taufik. 2011. Buku Pintar Investasi Syariah (Cetakan Pertama). Jakarta: Mediakita.

Ikatan Akuntan Indonesia. 2007. Standar Akuntansi Keuangan Per 1 September 2007. Jakarta: Salemba empat.

James C. van Horne dan John M. Wachowicz. 2012. Prinsip-prinsip manajemen keuangan. Jakarta: Salemba Empat.

Kanadi, hendrik. 2010. Membuat Report Akuntansi Tanpa Repot dengan Excel 2007. Jakarta: PT Elex Media Komputindo.

Kuswandi. 2008. Memahami Rasio-Rasio Keuangan Bagi Orang Awam. Jakarta: PT Elex Media Komputindo.

Mardiyanto, Handoyo. 2008. Intisari Manajemen Keuangan. Jakarta: Grasindo.

Martono dan Agus, Harjito D.2010. Manajemen Keuangan Ekonisia Kampus Fakultas Ekonomi UII. Yogyakarta.

Mulyana, M. and Puspitasari, R., 2014. Analisis Faktor-faktor Yang Membentuk Minat Berwirausaha Siswa SMK di Kota Bogor.

Mulyana, M. and Maulana, M., 2013. Pengaruh Pelayanan Terhadap Kepuasan Pelanggan dan Implikasinya Terhadap Citra Perusahaan. Jurnal Ilmiah Manajemen Kesatuan, 1(2). 
Ross, Westerfield. 2009. Pengantar Keuangan Perusahaan Edisi 8. Jakarta: Salemba Empat.

Standar Akuntansi Keuangan. 2007. Standar Akuntansi Keuangan Per 1 September 2007. Jakarta: Salemba Empat.

Stephen A. Ross, Randolph W. Westerfield, Bradford D. Jordan. 2009. Pengantar Keuangan Perusahaan. Jakarta: Salemba Emapat.

Sugiono, Arif dan Untung, Edy. 2008. Panduan Praktis Dasar Analisa Laporan Keuangan. Jakarta: Grasindo. 